\title{
Selected Chemical Aspects of Nuclear Power Development
}

\author{
Andrzej G. Chmielewski, Marcin Brykala, Tomasz Smolinski \\ Institute of Nuclear Chemistry and Technology, Warsaw, Poland \\ Email: a.chmielewski@ichtj.waw.pl
}

Received July 30, 2012; revised September 1, 2012; accepted September 11, 2012

\begin{abstract}
The Fukushima nuclear power plant (NPP) accident consequences are a new challenge for nuclear power development; however the sequence of the event has illustrated importance of radiation- and radiochemistry processes on the safe operation and shut down of nuclear reactor and decontamination of formed liquid and solid wastes. A chemistry program is essential for the safe operation of a nuclear power plant. It ensures the integrity, reliability and availability of the main plant structures, systems and components important to safety, in accordance with the assumptions and intent of the design. The proper implementation of these procedures minimizes the harmful effects of chemical impurities and corrosion on plant structures, systems and components. It supports the minimization of buildup of radioactive material and occupational radiation exposure as well as limiting of the release of chemicals and radioactive material to the environment [1].
\end{abstract}

Keywords: Chemistry; Nuclear Safety; Water Radiolysis; Radioactive Waste Treatment

\section{Introduction}

The history of radiochemistry has started over hundred years ago. The first separation scheme was developed by Maria Skłodowska-Curie and Pierre Curie [2]. The biggest development of the science was related to military and peaceful applications of fissile and radioactive elements in nuclear power, industry and medicine. The role of chemistry in the present safe and effective operation of all stages of nuclear power related technology is unquestionable.

The Polish Government decided to lunch a Polish Nuclear Energy Program which assumes the construction NPP by the year 2023. The Institute of Nuclear Chemistry and Technology (INCT, known in Poland as IChTJ) have elaborated own programme considering a role of their expertise in radiochemistry, radiation chemistry, radiobiology and radiometric methods to support of this programme. The construction of the Center of Radiochemistry and Nuclear Chemistry for Nuclear Power and Nuclear Medicine has been completed this year.

\section{Chemistry and Safety}

\subsection{Radiomonitoring, Radioecology and Emergency Preparedness}

Monitoring of fuel clad integrity, the first and the most important barrier against radioactivity release into the environment, is the most important line of process radiation monitoring at nuclear power installations (NPIs).
Current radioanalytical methods for detection of such radionuclides are usually difficult and time consuming, they require a great effort for sample separation and long-time measurements. Inductively coupled plasma mass spectrometry (ICP-MS) can be a complementary method to radiometric ones. ICP-MS methods of radionuclide determination have started to be developed since the last 15 years. In the INCT works on ICP-MS methods for U, Pu, ${ }^{90} \mathrm{Sr},{ }^{241} \mathrm{Am}$ are being carried out. The procedures are developed mainly for application to environmental analysis and preparation of test materials for proficiency tests on radionuclide determination which the INCT is a provider [3].

\subsection{Coolant Chemistry, Reactor Elements Corrosion and Decontamination of the Primary Circuit}

Coolant chemistry and reactor elements corrosion plays a very important role in nuclear engineering, covering all aspects of water radiolysis in boiling water reactor (BWR) and pressurized water reactor (PWR) units, effects of radiolytic phenomena on corrosion, etc.

There are three main tools used to handle reactor coolant system chemistry: $\mathrm{pH}$ control, zinc injection and dissolved hydrogen [4].

Decrease in $\mathrm{pH}$ of the water causes corrosion of metal equipment and destruction of water supply. Optimal $\mathrm{pH}$ of primary water approximately $7.2+/-0.2$ is recommended, because that minimizing the solubility and cor- 
rosion of the surfaces of the main components in the primary system, the difference of solubility and thus of transport of radioactivated isotopes in the various parts of the system at different temperatures, typically in the $270^{\circ} \mathrm{C}-325^{\circ} \mathrm{C}$ range. In practice, if the duration of a fuel cycle is extended 18 months or more is extending, it meant that the boron concentration at the beginning of cycle had to be raised from 1200 to $1800 \mathrm{mg} / \mathrm{kg}$ (ppm). This requires a lithium concentration greater than 2.2 $\mathrm{mg} / \mathrm{kg}$ to maintain optimum $\mathrm{pH}$.

The correct $\mathrm{pH}$ of water is very important for minimum solubility of nickel ferrite, which is the major component of CRUD. It is product of corrosion, mainly $\mathrm{R}_{3} \mathrm{O}_{4}(\mathrm{R}=\mathrm{Fe}, \mathrm{Ni}$ or $\mathrm{Cr})$, and a ratio of these elements depends on the type of construction material and type of reactor. Crud circulates inside the cooling system and in the vicinity of the core is activated, then settles on poorly secured locations of pipes, cooling system components and etc., which is a major threat.

The next tool used to handle reactor coolant system chemistry is addition of zinc, where is used zinc's affinity for the tetrahedral sites of spinel oxide minerals' structure. Thus, it can displace other cations such as iron, or nickel from oxide films, which activates into ${ }^{58} \mathrm{Co}$, a major radioelement. Zinc is added at a concentration of about $5 \mu \mathrm{g} / \mathrm{kg}$ (ppb), which is sufficient to reduce the dose rates by $15 \%$ during the first fuel cycle and up to $30 \%$ to $40 \%$ after a few cycles with zinc injection. Relatively high cost of zinc depleted $\left({ }^{64} \mathrm{Zn}\right)$ salts causes searching new additives like aluminum salts. A study by gel chromatography in combination with radioisotope and elemental analyses showed that the Co(II) ions incorporated in polymeric hydrolysis products in the step of their formation were practically fully replaced by aluminum ions in the course of the polymer aging. Because such polymers are precursors of loose corrosion product deposits formed in primary circuits of NPIs and incorporating the most radiation-hazardous radionuclide ${ }^{60} \mathrm{Co}$, addition of aluminum salts to primary coolants improves the radiation situation in the maintenance area of NPIs and, therefore, can be appropriate solution [5].

The third important tool to handle reactor coolant system chemistry is to optimize hydrogen concentration, applied to mitigate water radiolysis. For a long time, a value of 25 - $35 \mathrm{ml} / \mathrm{kg}$ (within a range of 25 - 50) has been used. The US Electric Power Research Institute (EPRI) is considering increasing the hydrogen concentration towards $50 \mathrm{ml} / \mathrm{kg}$ and possibly beyond, depending on the results of the ongoing qualification work on the risk of decreasing the time to crack initiation. The intention is to minimize crack growth rates. However, Japanese utilities are evaluating the action of decreasing hydrogen concentration to delay crack initiation.

On the other hand, the knowledge of radiolytic proc- esses governed by physics and chemistry plays a very important role in the development of fuel reprocessing technologies, waste reprocessing and spent fuel and conditioned waste storage.

One of the challenges of chemistry is decontamination coolant water. It is necessary to establish precise chemistry to achieve optimum results. There are a lot of chemical and physical processes used to decontaminate coolant. It is used ion exchangers, solvent extraction and membrane methods. Water in primary coolant circle might be contaminated by fission products for example cesium or strontium. It might be removed from coolant by using special sorbents. In INCT by J. Narbutt groups synthetized sorbent to composite ion exchanger for selective removal radiocesium [6]. The sorbent allow to remove cesium ions from aqueous solutions containing cations of other metals.

\subsection{Fuel Reprocessing}

Generation IV reactor concepts and accompanying reprocessing technologies aqueous-based and pyrometallurgical, is a new challenge from the chemistry point of view [7]. Mainly, how to reduce the cost and to improve the safety of the management of such high-level nuclear waste are being considered.

An advanced closed fuel cycle relies on the possibility to maximise the energy usage of nuclear spent fuel and to provide improved waste forms for long-term storage: the removal of minor actinides (i.e.: $\mathrm{Np}, \mathrm{Am}, \mathrm{Cm}, \mathrm{Cf}$ ) with $\mathrm{U}$ and $\mathrm{Pu}$ from the waste and in some cases long-lived fission products (LLFP: ${ }^{99} \mathrm{Tc},{ }^{129} \mathrm{I}$ and ${ }^{135} \mathrm{Cs}$ ) and heat generation fission products $\left({ }^{90} \mathrm{Sr}\right.$ and $\left.{ }^{137} \mathrm{Cs}\right)$, are partitioned by chemical separation. Separated all elements of significant Trans-Uranium (TRU) elements are immobilizated or transmutated in either a thermal or in fast neutron reactors [8] into short-lived or stable isotopes prior to disposal.

Various technologies of partitioning, based on hydrometallurgical processes, were developed to extract the minor actinides from nuclear waste - an acidic $\left(\mathrm{HNO}_{3}\right)$ solution as a rule, the aqueous raffinate, which remains after recovering uranium and plutonium in the solvent extraction process PUREX [9]. The technique can also be extended for the recovery of neptunium, but separation of trivalent americium and curium from trivalent lanthanides ( $\mathrm{Ln}$ ) cannot be separated directly in this process. Studies on solving of this issue are carried out for decades by many research teams.

Therefore, two steps of separations processes are at present considered. In the first step, at high acidity, a group separation of MA and lanthanides is carried out, followed by a selective separation of MA from lanthanides at lower acidity.

In this technology developed by the EU consortium 
coordinated by C. Madic, in the first step the minor actinides are directly extracted from the PUREX raffinate together with fission lanthanides as nitrates, using diamide extractants - the malonamides or diglycolamides (DIAMide EXtraction process) [10]. Various extraction systems were studied for the second step. The MA (III) + Ln (III) mixture generated after this first step is lowacidic to facilitate the second process, the SANEX process (Selective ActiNide EXtraction), which the goal is to separate the trivalent An from the Ln directly from the DIAMEX product. This process is based on the BTP, which belongs to a new family of extractants, the BisTriazinyl-Pyridine developed by Z. Kolarik et al., and is very efficient for a selective extraction of MA (III) at high acidity [11] and shows good capabilities in centrifugal extractors.

The EU ACSEPT project in which INCT is active plays a very important role to achieve the progress in the chemical separations field [12]. One of the concept of ACSEPT project is optimize of GANEX (Group ActiNide EXtraction) In the second cycle of separation of actinides from lanthanides is possible, as well as from other fission products. Objective is achieved by using as the organic phase of extraction mixture of bis-triazinebipyridine (BTBP) and tri-n-butyl phosphate (TBP) in cyclohexanone. The aqueous phase contains $4 \mathrm{M}$ nitric acid, actinides, and lanthanides, and FP. BTBP molecules containing soft-donor nitrogen atoms favoring complexation of actinide $5 \mathrm{f}$ orbitals have the ability to separate actinides (III, IV, V and VI) from lanthanides (III). The TBP allows the extraction of uranium and plutonium [13].

One promising concept after the partitioning step is embedding the minor actinides (MA: Am, Cm, Cf) in uranium-based nuclear fuel by sol-gel process. This will allow the MAs to be destroyed by fast-neutron reactions in the upcoming generation-IV reactors.

Even a manufacturing of uranium oxide fuels is well developed process, synthesis of mixed uranium-MA fuels is a process under development. At the INCT a new variant of a sol-gel method called-Complex Sol-Gel Process (CSGP) has been elaborated to obtain uranium dioxides (Patent Pending-[14]). This method has been used to synthesis of uranium dioxides doped by neodymium, as surrogates of trivalent plutonium and americium. The main modification step is the formation of uranylneodymium-ascorbate sols from components alkalized by aqueous ammonia. Those sols were gelled into: 1) irregularly agglomerates by evaporation of water; 2) medium sized microspheres (diameter $<100 \mu \mathrm{m}$ ) by INCT variant of sol-gel processes by water extraction from drops of emulsion sols in 2-ethylhexanol-1 by this solvent (Figure 1). Uranium dioxide was obtained by a reduction of gels with gas mixture of argon and hydrogen at temperatures $900^{\circ} \mathrm{C}$ [15]. The work has been carried out within the collaborative Project ACSEPT (Actinide Recycling by Separation and Transmutation), contract No. FP7-CP2007-211267. Continuations of this work carry out within the collaborative Project ASGARD (Advanced for Generation IV reactors: Reprocessing and Dissolution, contract No. FP7-CP-2011-295825).

In frame of Strategic Project "Technologies Supporting Development of Safe Nuclear Power Engineering" Domain 4 "Development of spent nuclear fuel and radioactive waste management techniques and technologies" by the National Centre for Research and Development, in INCT, works for elaborated of method synthesis of uranium carbides and nitrides doped by surrogates of MA are carried out. By using of CSGP Process, finally carbides and nitrides will gelled into irregularly agglomerates and medium sized microspheres (diameter $<100$ $\mu \mathrm{m})$. The physical properties of carbide and nitride fuel make them attractive because they are conducive to high specific rod powers with relatively low fuel centre temperatures: start of life power capability is increased, power-to-melt margin is increased and fatter (more economic) pins are facilitated. Also, the very important advantages in case of transmutation is a higher actinide density to oxides. Because fuel temperatures are low, the fuel suffers little or no restructuring and the release of fission gases and volatile fission products is low $[16,17]$.

Other developed option of fuel to the incineration of plutonium and minor actinides in thermal reactors, fast reactors, and advanced systems are Inert Matrix Fuels (IMF). The desired properties of the material(s) are a

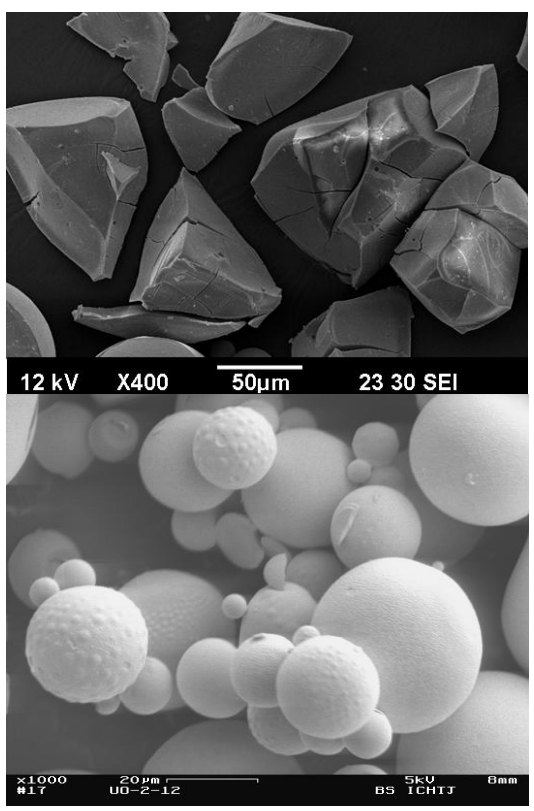

Figure 1. SEM analysis of uranium dioxide in the shape of irregular powders (top) and spherical particles (diameter below $100 \mu \mathrm{m}$ ) obtained by CSGP. 
high melting point, good thermal conductivity, good compatibility with the cladding, low solubility in the coolant, good mechanical properties, and high density. In all cases, the IMF candidate is compared to standard $\mathrm{UO}_{2}$ fuel as the reference [18,19]. A critical assessment of selection of materials as diluents for burning of plutonium fuels in nuclear reactors based on their physical and chemical properties are discussed in a recent review. This review appraises the out-of pile properties of $\mathrm{Al}_{2} \mathrm{O}_{3}$, $\mathrm{MgO}, \mathrm{MgAl}_{2} \mathrm{O}_{4}, \mathrm{CeO}_{2}, \mathrm{Ce}_{2} \mathrm{O}_{3}, \mathrm{Y}_{2} \mathrm{O}_{3}, \mathrm{ZrO}_{2}, \mathrm{CePO}_{4}$, $\mathrm{ZrSiO}_{4}, \mathrm{~B} 4 \mathrm{C}, \mathrm{SiC}, \mathrm{AlN}, \mathrm{Mg}_{3} \mathrm{~N}_{2}, \mathrm{Si}_{3} \mathrm{~N}_{4}, \mathrm{CeN}, \mathrm{YN}$ and $\mathrm{ZrN}$ include, e.g. melting point, vapour pressure and thermal conductivity; the chemical behavior towards steel, liquid sodium, water, air and nitric acid in the context of suitability of diluents [20].

In the task of the Strategic Project there was elaborated method of synthesis of zirconium dioxide doped by surrogates of MA (finally plutonium and MA). This method will be used to study of nuclear transmutation of long lived actinides to short-lived nuclides.

\subsection{Radioactive Waste Treatment}

All fuel cycles generate some types of long-lived radioactive wastes; thus the ultimate need for disposal of those wastes. The disposal of SNF and HLW has been a major technical and institutional challenge. The modern concept of safe management of high-level liquid radioactive wastes (HLRW) is strongly connected with reprocessing of nuclear spent fuel. It provides for the necessity in fractional separation of highly active components of these wastes including ${ }^{235} \mathrm{U}$ and ${ }^{239} \mathrm{Pu}$, minor actinides $\left({ }^{241} \mathrm{Am}\right.$, ${ }^{244} \mathrm{Cm}$, ${ }^{237} \mathrm{~Np}$ ), and fission products $\left({ }^{137} \mathrm{Cs}\right.$ and $\left.{ }^{90} \mathrm{Sr}\right)$ followed by their immobilization or transmutation into short-lived or stable isotopes prior to disposal [21]. Selective removal of radionuclides from the bottoms residue of evaporation equipment used in NPPs has an enormous advantage over the conventional methods currently being used to condition liquid radwastes (cementing, bituminization). The advantage is primarily due to the decrease in the volume of the conditioned wastes put into solid radwaste repositories.

The nuclear industry produces large volumes of radioactive solution waste, which requires treatment prior to final disposal or storage. A highly efficient treatment concept is the removal of harmful radionuclides from the bulk waste solution. Application of such a technique will result in considerable reductions in the volumes of waste that require solidification prior to final disposal, as well as in radioactive discharges from storage containers into the environment. Number of methods are used to treat aqueous radioactive wastes, including chemical precipitation, evaporation and ion exchange, as well as less developed solvent extraction, biotechnological processes and membrane methods.
Before final storage of HLW in geological repositories, wastes have to be immobilized and encapsulated. The possible water penetration and leaching of radionuclides from stored radioactive waste makes this problem very important issue. The standard material used to encapsulate fission products and minor actinides is the vitreous matrix. The main advantages of this type of containment matrix are that it is very leach-resistant (dissolution in water) and radiation-resistant material. It is relatively easy to produce on a technical level, and it can accommodate a wide range of radioelements in compact packaging.

The most significant disadvantage of glasses for such use is their high processing temperature of $\sim 2000^{\circ} \mathrm{C}$. Sintering of sol-gel-derived glasses can be accomplished at much lower temperatures, and sol-gel techniques have been successfully used for preparation of porous glass hosts for nuclear wastes [22,23]. Appropriately prepared, sintered ceramic bodies can have higher stabilities and be more resistant to leaching than are many melt-processed glasses [24]. In one frame of Strategic Project, researches in INCT are focused on elaborating of "cold" vitrification process and immobilization HLW in ceramic matrixes. Mentioned CSGP process [25] has been adapted to synthesize silica glasses capable of incorporating significant concentrations of high-level nuclear wastes. An example flow-chart for the preparation silica gels is shown in Figure 2.

Gels in the form of powders or monoliths were prepared by hydrolysis and subsequent polycondensation of tetraethoxide/me nitrate solutions containing ascorbic acid (ASC) as a catalyst, instead of the $\mathrm{HCl}$ or $\mathrm{NH}_{4} \mathrm{OH}$ that are routinely used for catalysis in glass synthesis.

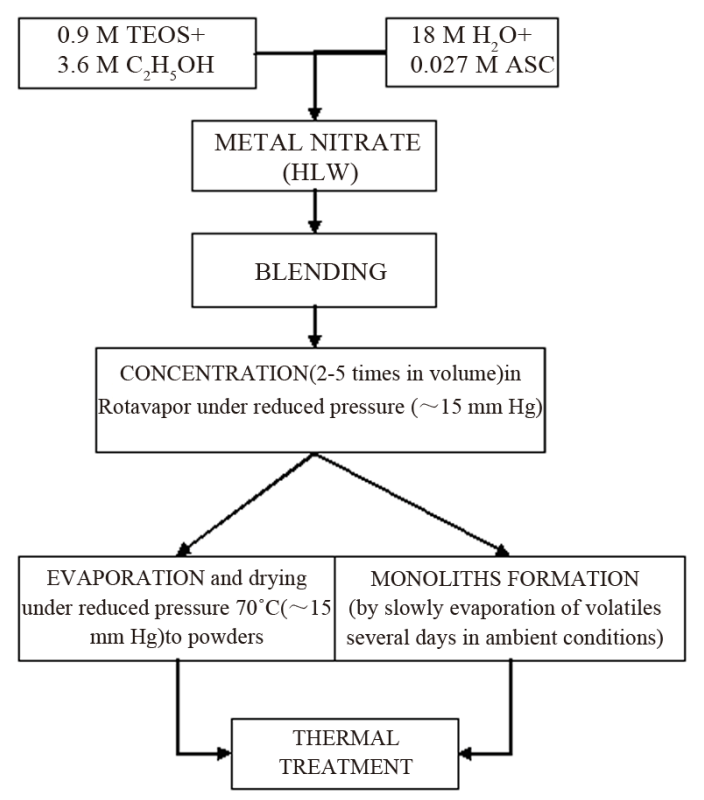

Figure 2. Flow-chart of CSGP for preparation of silica glass. 
The second task of the project is immobilization of radionuclides SYNROC materials [26]. The INCT sol-gel method of synthesis titanates are used to synthesis titanate matrixes for encapsulation nuclear wastes [27].

\subsection{Radio- and Radiation Chemistry in INCT Poland}

A chemistry program is essential for the safe operation of a nuclear power plant. Moreover in Polish situation, when Polish Government has lunched: "Program of development of nuclear energy in Poland" R \& D background has a key role. The only R \& D Institute in Poland which covers most of the fields of nuclear chemistry, radiochemistry, nuclear chemical engineering and radiation chemistry is the Institute of Nuclear Chemistry and Technology. The Institute runs the $\mathrm{PhD}$ studies in this field. Some researches of the Institute were presented earlier in the thematic chapters. Another R \& D unit the National Centre for Nuclear Research (NCBJ), Świerk was established in September 2011. NCBJ is strongly involved in developing nuclear reactor engineering and promoting practical applications of nuclear physics methods. Concerning the radiochemistry major market products manufactured in the NCBJ include radiopharmaceuticals and other radioisotopes. Other activities regarding radio- and radiation chemistry are ongoing at some universities. Regarding the radiochemistry, the most academic centers are working in the radioecology field Department of Radiochemistry and Colloid Chemistry, Faculty of Chemistry, Maria Curie-Skłodowska University. Lublin after Chernobyl accident focused its activities on defining a radiological state of environment - determination of the contamination level of soil, river and lake sediments, as well as ground level air with the anthropogenic isotopes such as: ${ }^{137} \mathrm{Cs},{ }^{90} \mathrm{Sr}$ and Plutonium. General research interest of the Analytics and Environmental Radiochemistry Chair at Faculty of Chemistry, University of Gdańsk, is focused on analytical chemistry and radiochemistry [28,29]; application of activity disequilibrium between ${ }^{210} \mathrm{Po} /{ }^{210} \mathrm{~Pb},{ }^{234} \mathrm{U} /{ }^{238} \mathrm{U},{ }^{238} \mathrm{Pu} /$ ${ }^{239}+{ }^{240} \mathrm{Pu}$ and ${ }^{241} \mathrm{Pu} /{ }^{239+}{ }^{240} \mathrm{Pu}$ as well as isotopic ratio ${ }^{240} \mathrm{Pu} /{ }^{239} \mathrm{Pu}$ for research on polonium, uranium and plutonium sources in the natural environment; impact of the Chernobyl accident on radioactive pollution; radiological risk of radionuclides intake with air, water and food consumption as well as cigarette smoking by consumers. The group working in the Department of Chemistry of the University of Warsaw has been engaged for years in the study of isotope effects on various physicochemical properties of chemical substances [30]. There are three research groups active in the field of radiation chemistry in Poland. One exists at the INCT and uses as a main experimental method nanosecond pulse radiolysis with UV/VIS detection based on the electron linear accelera- tor $10 \mathrm{MeV}$. The second is located at the Institute of Applied Radiation Chemistry (IARC), Technical University of Łodź equipped in PR1 - pulse radiolysis system using electron beam pulses of duration variable from $2.5 \mathrm{~ns}$ to $4.5 \mu \mathrm{s}$, dose per pulse from 2 Gy to $1 \mathrm{kGy}$, wavelength spectroscopic range $250-2000 \mathrm{~nm}$ at room temperature, recorded data time range from $500 \mathrm{~ns}$ to $2 \mathrm{~s}$ FS (full scale) with $1 \mathrm{~ns}$ resolution time. IARC is working on some aspects of radiochemistry as well. The third radiation chemistry group exists in the Chemistry Department of the University of Podlasie, Siedlce. Some aspects of radiochemistry and radiation chemistry developments are discussed by Narbutt [13] and Chmie- lewski [31].

INCT in collaboration with other institutions was responsible for chemistry program preparation, personnel training and pilot studies for NPP Żarnowiec. These are well known facts that this kind of knowledge is not being delivered in the frame of the most well elaborated contract. Technology provider will not guarantee full responsibility for the operations which has to be updated to the state of art available in the next 5 - 10 years. Moreover foreign suppliers will not able to provide an adequate training of a personnel to be employed in the given country conditions.

\section{Conclusion}

This paper has been prepared to underline the role of chemistry and its contribution to the nuclear energy power development. It shows only few aspects which connect chemistry with nuclear engineering, but it is just "the tip of the iceberg". Mostly, it is referring to the INCT and author's works. However, its content illustrate well the role of chemistry in the present safe and effective operation of all stages of nuclear power related technology. Hopefully, it will pay attention on this issue and stimulate researches in this field.

\section{Acknowledgements}

This paper has been prepared in frame of Strategic Project "Technologies Supporting Development of Safe Nuclear Power Engineering" Domain 4 "Development of spent nuclear fuel and radioactive waste management techniques and technologies" by the National Centre for Research and Development (SP/J/4/143 321/11).

\section{REFERENCES}

[1] International Atomic Energy Agency, "Chemistry Programme for Water Cooled Nuclear Power Plants," Specific Safety Guide No. SSG-13, 2011.

[2] J. Hurwic, "Maria Skłodowska-Curie and Radioactivity," Galant Edition, Warsaw, 2011.

[3] H. Polkowska-Motrenko and L. Fuks, "Proficiency Test- 
ing Schemes on Determination Of Radioactivity in Food and Environmental Samples Organized by the NAEA," Nukleonika, Vol. 55, No. 2, 2010, pp. 149-154.

[4] F. Nordmann, "PWR and BWR Chemistry Optimatization," Nuclear Engineering International, Vol. 56, No. 689, 2011, pp. 24-29.

[5] T. V. Epimakhov, L. N. Moskvin, A. A. Efimov and O. Y. Pykhteev, "Positive Effect of Adding Aluminum Salts to Primary Coolants of Nuclear Power Installations," Radiochemistry, Vol. 52, No. 6, 2010, pp. 581- 584.

[6] J. Narbutt, "Inorganic Ion Exchangers as Selective Adsorbents and Potential Primary Barriers for Radionuclides," In: The Environmental Challenges of Nuclear Disarment, Kluver Academic Publishers, Netherlands, 2000, pp. 237-243.

[7] D. Olander, "Nuclear Fuels_-Present and Future," Journal of Nuclear Materials, Vol. 389, No. 1, 2009, pp. 1-22. doi:10.1016/j.jnucmat.2009.01.297

[8] Nuclear Energy Agency, "National Programmes in Chemical Partitioning. A Status Report," NEA No. 5425, Nuclear Energy Agency, Organization for Economic CoOperation and Development, 2010.

[9] J. N. Mathur, M. S. Murali and K. L. Nash, "Actinide Partitioning-A Review," Solvent Extraction and Ion EXchange, Vol. 19, No. 3, 2001, pp. 357-390. doi:10.1081/SEI-100103276

[10] C. Madic, F. Testard, M. J. Hudson, et al., "PARTNEWNew Solvent Extraction Processes for Minor Actinides," Final Report, CEA-R-6066, 2004.

[11] Z. Kolarik, U. Müllich and F. Gasner, "Selective Extraction of Am(III) over Eu(III) by 2,6-Ditriazolyl- and 2,6Ditriazinylpyridines," Solvent Extraction and Ion Exchange, Vol. 17, No. 1, 1999, p. 23. doi:10.1080/07360299908934598

[12] J. Narbutt, "Hydrometallurgic Separation of Minor Actinides from High Active Nuclear Waste for Their Transmutation-Collaborative Project ACSEPT, 7. Framework Programme, EU, Euratom," V Polish Conference on Radiochemistry and Nuclear Chemistry, Kraków, 24-27 May 2009, p. 2.

[13] J. Narbutt, "Trends in Radiochemistry at the Beginning of the 21st Century," Nukleonika, Vol. 50, Suppl. 3, 2005, pp. S77-S81.

[14] A. Deptuła, M. Brykała, W. Łada, D. Wawszczak, T. Olczak and A. G. Chmielewski, "Method for Preparing of Uranium Dioxide in the Form of Spherical and Irregular Grains," Polish Patent Pending No. P-389385 (27-10-2009), European Patent Application No. 10188438.5-1218 (2010), Russian Federation Patent Application 2010136670 (2010), Belarus Patent Application 20101305 (2010), Ukraine Patent Application 201010756 (6-09-2010).

[15] A. Deptuła, M. Brykała, W. Łada, D. Wawszczak, T. Olczak, G. Modolo, H. Daniels and A. G. Chmielewski, "Synthesis of Uranium and Thorium Dioxides by Complex Sol-Gel Processes (CSGP)," Proceedings of the 3rd International Conference on Uranium, 40th Annual Hydrometallurgy Meeting, Vol. II, Saskatoon, 2010, pp. 145-154.

[16] K. Minato, M. Akabori, M. Takano, Y. Arai, K. Nakajima,
A. Itoh and T. Ogawa, "Fabrication of Nitride Fuels for Transmutation of Minor Actinides," Journal of Nuclear Materials, Vol. 320, No. 1-2, 2003, pp. 18-24. doi:10.1016/S0022-3115(03)00163-6

[17] International Atomic Energy Agency, "High Temperature Gas Cooled Reactor Fuels and Materials," International Atomic Energy Agency, Vienna, 2010.

[18] C. Degueldre, et al., "Plutonium Incineration in LWRS by a Once through Cycle with a Rock-Like Fuel," Materials Research Society Symposium Proceedings, Vol. 412, 1996, p. 15. doi:10.1557/PROC-412-15

[19] H. Kleykamp, "Selection of Materials as Diluents for Burning of Plutonium Fuels in Nuclear Reactors," Journal of Nuclear Materials, Vol. 275, No. 1, 1999, pp. 1-11. doi:10.1016/S0022-3115(99)00144-0

[20] International Atomic Energy Agency, "Viability of Inert Matrix Fuel in Reducing Plutonium Amounts in Reactors," International Atomic Energy Agency, Vienna, 2006.

[21] T. A. Maryutina, M. N. Litvina, D. A. Malikov, et al., "Multistage Extraction Separation of Am(III) and Cm(III) in Planet Centrifuges," Radiochemistry, Vol. 46, No. 6, 2004, pp. 596-602. doi:10.1007/s11137-005-0035-4

[22] T. Woignier, J. Reynes, J. Phalippou and J. L. Dussossoy, "Nuclear Waste Storage in Gel-Derived Materials," Journal of Sol-Gel Science and Technology, Vol. 19, No. 1-3, 2000, pp. 833-837.

[23] T. Woignier, J. Reynes, J. Phalippou and J. L. Dussossoy, "Sintered Silica Aerogel: A Host Matrix for Long Life Nuclear Wastes," Journal of Non-Crystalline Solids, Vol. 225, 1998, pp. 353-357. doi:10.1016/S0022-3093(98)00052-0

[24] D. R. Clarke, "Ceramic Materials for the Immobilization of Nuclear Waste," Annual Review of Materials Research, Vol. 13, 1983, pp. 191-218. doi:10.1146/annurev.ms.13.080183.001203

[25] A. Deptula, W. Lada, T. Olczak, M. T. Lanagan, S. E. Dorris, K. C. Goretta and R. B. Poeppel, "Method for Preparing High-Temperature Superconductors," Polish Patent No. 172618, 1997.

[26] A. E. Ringwood, "Immobilization of Radioactive Wastes in SYNROC," American Scientist, Vol. 70, No. 2, 1982, pp. 201-207.

[27] A. Deptula, K. C. Goretta, T. Olczak, W. Lada, A. G. Chmielewski, U. Jakubaszek, B. Sartowska, C. Alvani, S. Casadio and V. Contini, "Preparation of Titanium Oxide and Metal Titanates as Powders, Thin Films, and Microspheres by Novel Inorganic Sol-Gel Process," Materials Research Society Symposium Proceedings, Vol. 900E, 2005.

[28] B. Skwarzec, K. Kabat and A. Astel, "Seasonal and Spatial Variability of 210Po, 238U and $239+240 \mathrm{Pu}$ Levels in the River Catchment Area Assessed by Application of Neural-Network Based Classification," Journal of Environmental Radioactivity, Vol. 100, No. 2, 2009, pp. 167175. doi:10.1016/i.jenvrad.2008.11.007

[29] D. Strumińska-Parulska and B. Skwarzec, "Plutonium Isotopes ${ }^{238} \mathrm{Pu},{ }^{239+240} \mathrm{Pu},{ }^{241} \mathrm{Pu}$ and ${ }^{240} \mathrm{Pu} / 239 \mathrm{Pu}$ Atomic Ratios in Southern Baltic Sea Ecosystem," Oceanologia, 
Vol. 52, No. 3, 2010, pp. 499-512. doi:10.5697/oc.52-3.499

[30] A. Makowska, A. Siporska and J. Szydłowski, "Isotope Effects on Miscibility of 1-Alkyl-3-Methylimidazolium Bis(Trifluoromethyl)Sulfonyl Imides with Aromatic Hy- drocarbons," Fluid Phase Equilibria, Vol. 282, No. 2, 2009, pp. 108-112. doi:10.1016/j.fluid.2009.05.003

[31] A. G. Chmielewski, "Chemistry for the Nuclear Energy of the Future," Nukleonika, Vol. 56, No. 3, 2011, pp. 241249. 